Revista Mídia e Cotidiano

Editorial

Volume 1, Número 3, set./dez. de 2021

\title{
A informação e o mal: disputas éticas, políticas e epistemológicas da Comunicação em tempos extremos
}

\section{Information and evil: ethical, political and epistemological disputes of Communication in extreme times}

\section{Información y maldad: disputas éticas, políticas y epistemológicas de la Comunicación en tiempos extremos}

\author{
Marco SCHNEIDER ${ }^{1}$ \\ Marco Antônio BONETTI ${ }^{2}$ \\ Rogério CHRISTOFOLETTI ${ }^{3}$
}

Quando lançamos a chamada de textos para esta edição, encontramos na audácia de uma afirmação o horizonte que nos guiaria para compor este número. Escrevemos: "O mal da comunicação é a desinformação". À época, já reconhecíamos que a intensidade generalizadora da afirmação poderia ser contestada de imediato, embora algumas circunstâncias permitissem que enunciados desinformantes poderiam ser até benéficos, aceitáveis quando não desejáveis. Mencionávamos o caso de uma guerra: desorientar o inimigo pode ser estratégico, salvar vidas e levar à vitória de uma batalha, por exemplo. Mas a estratégia é um aspecto apenas de uma questão tão complexa e multifacetada que, inevitavelmente, é atravessada por dilemas e problematizações éticas.

Nos últimos meses, mergulhados no exigente processo de edição de Mídia e Cotidiano, tivemos a confirmação de algumas intuições sobre que contribuições colheríamos a partir da remessa de artigos que nos chegassem. A primeira intuição era de que muitos pesquisadores estão debruçados sobre o problema da desinformação, fator que enriquece o diálogo em nossa área, mas que, ao mesmo tempo, complexifica a definição de que artigos deveriam desfilar nas próximas páginas. Confirmamos tal intuição, o que nos encheu de doses generosas de entusiasmo e receio

\footnotetext{
1 Professor do Departamento de Comunicação da Universidade Federal Fluminense (UFF) e pesquisador do Instituto Brasileiro de Informação em Ciência e Tecnologia (Ibict). Email: art68schneider@gmail.com. ORCID: 0000-0001-5053-9491.

2 Professor da Faculdade de Comunicação da Universidade Federal de Juiz de Fora (UFJF). E-mail: marco.bonetti22@gmail.com. ORCID: 0000-0002-0130-0054.

3 Professor do Departamento de Jornalismo da Universidade Federal de Santa Catarina (UFSC). Pesquisador do CNPq (PQ-2). E-mail: rogerio.christofoletti@ufsc.br. ORCID: 0000-0003-1065-4764.
} 
pela responsabilidade que isso acarretava. A segunda intuição estava relacionada à expectativa de que, com este dossiê, poderíamos avançar um pouco mais na compreensão do tema e da constelação de conceitos que o cerca. Afinal, é de um contexto extremo que estamos tratando, marcado por ecossistemas enganadores, capitalismo de vigilância, propaganda preditiva e engenharias manipulativas, de um lado, e de agências checadoras de fatos, iniciativas de educação midiática e esforços de reafirmação das verdades e dos dados, de outro. Mais uma vez, pensamos que nossa intuição não estava tão distante de um horizonte realizável. Leitoras e leitores julgarão se isso se mantém dentro do razoável.

Nas próximas páginas, descortina-se uma paisagem informacional poluída, degradada, inédita e aparentemente indomável. Sua ubiquidade ocupa a maior parte do cotidiano de cada vez mais gente, onde viralizam novas mutações - fake news, deep fakes, pós-verdade - de velhos seres do mal da comunicação. Como também imaginávamos no início desta jornada, esta paisagem é também perfurada pelo evento mais transformador dos últimos tempos, a pandemia de Covid-19, que tem suas próprias expressões do desvio, do mal e da ruína. Em tempos excepcionais, a desinformação assume nuances extremas, dramáticas, profundas, conforme se verá mais adiante.

Desinformação, antivacina e políticas de morte propõe, na perspectiva foucaultiana da biopolítica, uma reflexão sobre como a chancela de agentes públicos à desinformação, particularmente aos movimentos antivacina, prejudica o combate à pandemia da Covid-19. O foco da análise é o pronunciamento do presidente da República que associa a vacinação contra a doença ao mito de "virar jacaré”. Já Comunicação digital e saúde da população. Análise da comunicação dos organismos e biopolítica em tempos de pandemia dialoga com Foucault, investigando o impacto da comunicação sobre a pandemia no Twitter, em relatos oficiais da Organização Mundial da Saúde, da Organização Pan-Americana da Saúde e do Subsecretário de Saúde do México, considerando a interação com seus seguidores.

Na sequência, Conspiracionismo e negacionismo político-midiático desvela articulações político-midiáticas calcadas em teorias conspiratórias, negacionismos, discursos populistas e de ódio, tendo como objeto vídeos sobre a pandemia do apresentador Sikêra Júnior. Os resultados sugerem uma estratégia comunicativa integrada entre mídia hegemônica e redes sociais enquanto Enquadramentos e desinformação sobre vacina contra COVID-19 no YouTube identifica casos de desordem informacional em narrativas de médicos, religiosos, youtubers e profissionais da comunicação, bem como narrativas de combate à desinformação, mediante análise de 50 frames de influenciadores brasileiros sobre vacinas contra a Covid-19 postados no YouTube em 2020, selecionados a partir do engajamento, considerando visualizações, comentários e likes. 
Seguindo, apresentamos no dossiê o texto Do cientista e sua (des)legitimação que discute a chamada 'crise da expertise' contemporânea. Como material empírico, o artigo analisa comentários negativos a uma postagem do biólogo brasileiro Atila Iamarino no Twitter. A análise evidencia resistência ao emprego de argumentação científica e o recurso recorrente à falácia $a d$ hominem. O próximo trabalho, A "vacina chinesa de João Doria": a influência da disputa política-ideológica na desinformação sobre a vacinação contra a Covid-19, insere no debate geral a influência das disputas ideológicas no WhatsApp, analisando vídeos com teorias da conspiração que recorrem ao discurso de autoridades médicas para se legitimarem enquanto $A$ persistência do misticismo, do senso comum e do mal nas receitas milagrosas contra a Covid-19: uma proposta de interpretação analisa mensagens sobre ingredientes e preparos com supostos efeitos curativos do novo coronavírus. A temática permite uma interessante reflexão sobre a relação entre religião, senso comum e o mal na interpretação da realidade, que mostra como essa interlocução pode favorecer a desinformação.

Os desafios para uma informação com credibilidade também são abordados em Acolhimento e resistência a correções de fake news na pandemia: a experiência do robô Fátima, da agência Aos Fatos, no Twitter. O artigo avalia a experiência da conta automatizada no Twitter, criada pela agência de checagem, para identificar e interagir com usuários dessa rede social que publicam informações falsas. E, finalmente, fechando a seção temática, trazemos Desafios e estratégias no combate à desinformação na Pandemia, que reflete sobre o papel do jornalismo no combate às fake news e na divulgação de informações no período pandêmico. O objeto de análise é o telejornalismo regional do MG1 e MG2 - Zona da Mata, da TV Integração acerca de um caso em Barbacena, Minas Gerais, envolvendo a Escola Preparatória de Cadetes do Ar (Epcar), entre maio e julho de 2020.

Já a Seção Livre tem início com o ensaio o "O espetáculo da vida vivida" e a história como vir a ser, no qual a professora Marialva Barbosa nos convida a pensar sobre o cotidiano presente, a partir de rearticulações possíveis do passado. A História é apropriada não em seu sentido habitual, como um tempo vivido, mas como um passado utópico, fruto de exercício da imaginação. Em estilo poético, o texto foi redigido a partir de ideias e reflexões expostas em abril deste ano, durante palestra de Marialva para o lançamento do livro Mídia e Cotidiano: uma cartografia de pesquisas (2021), organizado por docentes deste programa de pós-graduação. Em seguida temos o artigo Carnavalização bakhtiniana e o arquétipo bobo da corte na produção do Porta dos Fundos, que toma a reflexão de Mikhail Bakhtin sobre o riso medieval como referencial de análise dos vídeos Pena e Lulonaro, do grupo humorístico Porta dos Fundos. Em seguida, $O$ 


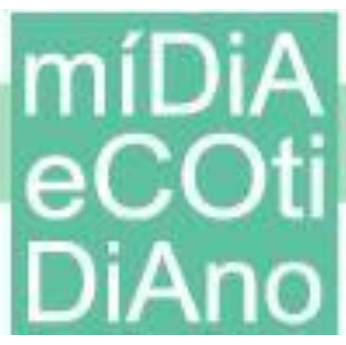

malandro no cinema: atualização da figura do malandro em Madame Satã, de Karim Aünouz discute as apropriações do cotidiano por meio dessas personagens na cinematografia brasileira. $\mathrm{O}$ texto historiciza tais aparições, buscando compreender de que modo tais figurações ajudam a (re)construir contextos sociais e culturais em diferentes momentos da sociedade brasileira.

O penúltimo texto da Seção Livre, Resistência constitucional, sociedade civil interveniente e princípio poliárquico: horizontes de sobrevivência para a Empresa Brasil de Comunicação, discute a necessidade de uma política democrática para a comunicação pública no Brasil e analisa as experiências exitosas de outros países em articulação com uma reflexão teórica sobre a economia política da informação, da comunicação e da cultura no país. Também olhando para o país e, de certo modo, em diálogo com o dossiê desta edição, o artigo que fecha a Seção, Negacionismo em textos acadêmicos no Portal de Periódicos Capes, traz um mapeamento das publicações sobre o assunto, nas ciências humanas e sociais, entre os anos de 2009 e 2020 para investigar a produção bibliográfica brasileira do fenômeno contemporâneo do negacionismo.

Nesta edição da Revista Mídia e Cotidiano iniciamos a "Seção Traduções". A proposta, aqui, é trazer textos de autores que contribuem, significativamente, para nossas pesquisas e reflexões. Inaugurando este espaço temos a tradução para o português de uma compilação de palestras do historiador norte-americano Jason Steinhauer sobre o tema das fake news e seu correlato no universo da História, que ele conceitua como fake History. Num texto introdutório, os tradutores apresentam este e alguns outros conceitos desenvolvidos por Steinhauer, no contexto de sua pesquisa sobre o papel do conhecimento histórico na vida pública. Também focando o tema tratado no dossiê a Seção Entrevistas traz duas contribuições. A primeira, de Ana Regina Rêgo, pesquisadora e professora da Universidade Federal do Piauí, idealizadora e coordenadora da Rede Nacional de Combate à Desinformação (RNCD) e, a segunda, do filósofo mexicano Fernando Buen Abad Domínguez, professor titular da Universidad Nacional de Lanús, Buenos Aires, que apresenta sua teoria da semiótica crítica e sua concepção do fenômeno das fake news como um elemento da dominação simbólica do capital em meio à configuração atual da luta de classes.

Finalmente, encerrando esta última publicação de 2021, temos a resenha que nos apresenta o livro Psicopolítica: o neoliberalismo e as novas técnicas de poder, do filósofo sulcoreano Byung-Chul Han. O autor, que vem se tornando conhecido do público brasileiro a partir de sua reflexão sobre a Sociedade do cansaço (HAN, 2015), nesta obra retoma o grande tema da relação entre o neoliberalismo e a vida psicológica dos indivíduos ao mostrar como as pessoas vêm submetendo a si mesmas a uma autoexploração produtiva permanente. 
Com estas contribuições dos autores e a decisiva participação dos pareceristas que mais uma vez foram parceiros da Revista Mídia e Cotidiano, esperamos que as próximas páginas tragam mais luz sobre as zonas sombrias onde reinam o mal e a desinformação. Que as vozes presentes ao longo do dossiê e dos demais textos também suscitem mais questionamentos e mais reflexão sobre as condições abrasivas e incontornáveis desses nossos tempos.

Boa leitura!

Marco Schneider, Marco Antônio Bonetti e Rogério Christofoletti (Ed. da Seção Temática) Denise Tavares, Isabella Rega, Larissa Morais e Renata Tomaz (Ed. da Seção Livre)

\section{Referências Bibliográficas}

HAN, Byung-Chul. Sociedade do cansaço. Tradução de Enio Paulo Giachini. Petrópolis, RJ: Vozes, 2015.

MORAIS et al. (orgs). Mídia e Cotidiano: uma cartografia de pesquisas. Rio de Janeiro: Letra Capital, 2021. 